\title{
Two notions of scientific justification
}

\author{
Matthias Adam \\ forthcoming in Synthese $e^{*}$
}

\begin{abstract}
Scientific claims can be assessed epistemically in either of two ways: according to scientific standards, or by means of philosophical arguments such as the no-miracle argument in favor of scientific realism. This paper investigates the basis of this duality of epistemic assessments. It is claimed that the duality rests on two different notions of epistemic justification that are well-known from the debate on internalism and externalism in general epistemology: a deontological and an alethic notion. By discussing the conditions for the scientific acceptability of empirical results, it is argued that intrascientific justification employs the deontological notion. Philosophical disputes such as those on scientific realism can by contrast be shown to rest on the alethic notion. The implications of these findings both for the nature of the respective epistemic projects and for their interrelation are explored.
\end{abstract}

\section{Scientific and philosophical assessments of science}

The justification of scientific claims regularly displays a familiar, yet puzzling ambiguity. Scientific theoretical claims, for instance, can on the one hand be justified according to the scientific standards, e.g. by being confirmed by specific empirical evidence and by possessing theoretical virtues such as simplicity and explanatory power. On the other hand, in disputes on scientific realism, the epistemic status of scientific theories and standards of confirmation is discussed with reference to philosophical arguments such as the abductive no-miracle argument or Laudan's pessimistic meta-induction (Boyd 1984, Laudan 1981). In a similar way, empirical results are acceptable as evidence in science if, for instance, expected errors are controlled or corrected and our theoretical understanding of the measurement process supports the reliability of the results. At the same time, philosophical investigations of the theory-dependence of observation consider under which conditions empirical results that rely on theoretical reasons are acceptable (for instance Brown 1989; Kosso 1989; Culp 1995; Adam 2004). One might well wonder which questions of justification remain to be settled by the philosophical discussions if theories or observations have already been assessed scientifically. It might seem that in both cases, the philosophical assessment in some way duplicates the epistemic assessment

\footnotetext{
The original publication will be available at www.springerlink.com, http://www.springerlink.com/openurl.asp?genre=article\&id=doi:10.1007/s11229-006-9052-x.
} 
that is already an integral part of scientific practice. The questions therefore arise in which respects the two kinds of assessment - intrascientific and philosophical differ, what their respective roles are, and how they relate.

According to the view that appears to be widely accepted in the philosophy of science, the two assessments both make sense since they are concerned with two different levels of assessment. While the scientific assessment evaluates scientific factual claims on the basis of methodological standards, the philosophical enterprise is seen to focus on the justification of the methodological standards themselves. According to this view, the main epistemological concern of the philosophy of science is methodological, and thus does not primarily address the epistemic status of scientific factual claims.

Imre Lakatos is a prominent advocate of such a view. According to him, the epistemological task of the philosophy of science is to build a theory of scientific rationality, i.e. a theory of the standards that define the scientific method. As he sees it, this theory should be tested against the "basic value judgments" of leading scientists. The philosophical theory is confirmed if it successfully reproduces the methodological decisions taken by the scientific élite. The philosophical aim is to explicate the standards of rationality implicit in the scientific method (Lakatos 1971). In Lakatos' view, the proper objects of the philosophical accounts are thus methodological standards and methodological decisions, not factual scientific claims.

Larry Laudan has a different, yet also methodological view of the role of the philosophical assessment. According to Laudan, the aim of the philosophy of science is to evaluate the effectiveness of the scientific methodological standards in furthering the epistemic aims of science. Contrary to Lakatos, the evaluation of these standards is not based on what the scientists themselves or the scientific community of their time took to be good scientific method, but depends on the standards' instrumental value for what we take to be the scientific epistemic ends (Laudan 1984, 1987). Still, also in Laudan's picture, the philosophical epistemic enterprise is primarily concerned with methodological standards, not with factual scientific claims.

Also in the disputes on scientific realism, the philosophical project is often portrayed as being mainly methodological, even though the position of scientific realism as such is explicitly concerned with the likely truth of scientific theories and thus with the epistemological status of scientific claims (see section 5). Still, Arthur Fine, for instance, distinguishes two levels of reasoning within Richard Boyd's 
prominent conception of scientific realism. On the ground level, scientists are seen to use rules of abductive reasoning to draw inferences from observables to unobservables. On the philosophical meta-level, the question is addressed why the scientific methods - including the rules for scientific ground-level abductive reasoning - are empirically successful. The position of scientific realism is taken to be located on the meta-level (Fine 1984, 84). ${ }^{1}$ Yet, if the philosophical arguments are primarily concerned with the methodological level, only the ground-level reasoning seems to address properly the epistemic status of theoretical scientific claims. Fine therefore concludes that it is altogether sufficient if one's theoretical beliefs are "tutored by ordinary relations of confirmation and evidential support, subject to the usual scientific canons" (Fine 1984, 98). Any additional philosophical assessment of scientific theoretical claims, as implied in scientific realism, would only add a "deskthumping, foot-stamping shout of 'Really!'” (Fine 1984, 97). A division of labor between scientific and philosophical assessments along the lines of the distinction of levels thus appears to make incomprehensible how philosophical arguments can address the epistemic status of scientific factual claims.

Against these positions, I argue in this paper that the division of labor between the intrascientific and the philosophical assessment cannot be analyzed by reference to the distinction between the justification of factual claims and the justification of methodological standards. Instead, I maintain that the philosophical assessment is often primarily concerned with the epistemic status of factual claims as well. Still, the philosophical assessment does not duplicate the intrascientific assessment, since the two assessments differ with respect to the employed notion of epistemic justification. While the scientific assessment makes use of a 'deontological' notion of justification, the philosophical evaluation uses an 'alethic' notion. This analysis leads to a new understanding of the relationship between philosophical and scientific epistemic evaluations. While they both mainly concern factual scientific claims, they divide the justificatory labor by differing in scope and range of reasons adduced, with the philosophical assessment being fairly general and being often based on rather broad assumptions on our epistemic situation, while the scientific assessment

\footnotetext{
Richard Boyd supports the impression that the concern of scientific realism is primarily methodological by claiming that the abductive no-miracle argument aims to explain why the scientific method regularly leads to the acceptance of empirically adequate theories (Boyd 1990). According to him, it is "the business of scientific epistemology to explain the reliability of [principles of scientific methodology]" (Boyd 1973, 3).
} 
concerns particular claims and is based on specific scientific reasons. The conceptual relationship between the two notions of justification leads to an intricate interdependence of the two types of epistemic assessment.

Since the distinction between the deontological and the alethic notion of justification features prominently in the discussions on internalism and externalism in general epistemology, I will first explicate the distinction by reference to this debate (section 2). Then, I will show by a number of examples that the different notions in fact underlie intrascientific viz. philosophical assessments (sections 3 to 5). Finally, I will defend the new analysis against the traditional distinction between assessments of factual claims and of methodological standards, and explore the relationship between science and the philosophy of science and their division of justificatory labor to which the new distinction of epistemic assessments gives rise (section 6).

2. Two notions of epistemic justification and the internalism-externalism debate in epistemology

In general epistemology, one often finds two different notions for assessing the epistemic justification of beliefs from a third-person perspective. William P. Alston has provided a representative characterization of the two notions by distinguishing between a "deontological" and an "evaluative" concept of epistemic justification (Alston 1985 and 1988). According to the deontological concept of justification (“J"J"),

$\mathrm{S}$ is $\mathrm{J}_{\mathrm{d}}$ in believing that $p$ iff in believing that $p \mathrm{~S}$ is not violating any epistemic obligations (Alston 1985, 86),

where the epistemic obligations of the subject S might, for example, "include to refrain from believing that $p$ in the absence of sufficient evidence and to accept whatever one sees to be clearly implied by something one already believes" (ibid.). According to the deontological concept, the beliefs of a person are justified if she fulfils in her believing the epistemic obligations that apply to her. According to Alston, there is a subjective aspect to the epistemic obligations that apply since a person can only be required to believe or refrain from believing to the extent that it is indicated by the facts accessible to her. Of course, this need not relieve the subject of the duty to seek additional evidence if it must be apparent to her that this is necessary. However, the status of her beliefs as justified or not justified cannot be 
made dependent on evidence that is completely beyond her epistemic perspective. ${ }^{2}$ Instead, she is free from blame and thus deontologically justified in her believing if she has done what can reasonably be expected from her (Alston 1988, 145).

According to the evaluative or "strong" (Alston 1988, 144) concept of justification ("Je"), by contrast,

$\mathrm{S}$ is $\mathrm{J}_{\mathrm{e}}$ in believing that $p$ iff $\mathrm{S}$ 's believing that $p$, as $\mathrm{S}$ does, is a good thing from the epistemic point of view (Alston 1985, 97).

The idea behind this second concept is that S's believing that $p$ is evaluated with respect to whether it is good from the point of view of the aim of our epistemic efforts. Since we aim to believe what is true and not to believe what is false, ${ }^{3}$ the evaluation of the subject's beliefs turns on whether it is likely that the beliefs are true or whether they were formed in a way that is generally truth-conducive (Alston 1988, 144). Since according to this second notion, justification is specified in terms of truth as the aim of our epistemic practices, I will refer to this concept as the alethic notion of justification.

The two notions of justification and their differences play an important role in the debate between internalism and externalism in epistemology (cp. Foley 1998, §3; Kornblith 2001a, 6). Roughly speaking, internalism is the view that the justification of a subject's beliefs can only depend on facts (states, events ...) that are internal to the subject, while externalism is the denial of such a constraint on the range of justifying items. More precisely, internalists typically hold that only the mental facts of a subject to which the subject has some special access - e.g. direct or introspective

2 Cp. Alston (1985, 86-89) for the distinction of the different ways of understanding epistemic obligations and for the defense of the moderately subjective (in Alston's terms: "cognitive") understanding.

3 In order to make clear that the epistemic aim cannot be reached trivially - e.g. believing only the obviously true or by refraining from any beliefs -, the aim can be put as being to maximize truth and to minimize falsity in a large body of beliefs (cp. Alston 1985, 84-85). Further qualifications of this epistemic goal have been proposed with respect to the significance of the sought beliefs (see Kitcher [2001, chapter 6] for the discussion specifically of scientific significance). I understand truth to be objective and substantial in the rough sense that the truth of a factual belief is independent from the holder of the belief and from her community and has implications for what entities exist or which facts hold. Still, as the sections 4 and 5 show, the two notions for justification can also be distinguished if one presupposes more restrained, anti-realist epistemic aims, e.g. empirical success viz. truth only of the non-theoretical scientific claims. However, justification in this more restricted sense would only license belief of the empirical content of scientific theories instead of full belief (see van Fraassen 1980). 
access - can be relevant for the justification of her beliefs. ${ }^{4}$ Externalism as the negation of internalism thus claims that the justification of a subject's beliefs can depend on factors to which the subject does not have special access or which need not be part of the subject's mental life. Most prominently, according to the externalist position of reliabilism, a belief is justified if it is generated or sustained by reliable mechanisms of belief formation, i.e. by mechanisms that generally produce true beliefs (Goldman 1979).

Given these distinctions, it seems reasonably clear that alethic justification will often be externalist. When we form beliefs about the empirical world using, e.g., perception, testimony or inductive reasoning, it will typically depend on many facts that lie beyond the range of internalist accessibility whether the beliefs are likely to be true. There could thus be pairs of situations which are equivalent with respect to the evidence that is internalistically accessible to subjects, yet which differ substantially with respect to the truth-conduciveness of the belief formation. An assessment of the alethic justification of empirical beliefs will in these cases have to take external circumstances into account.

Internalism, by contrast, has usually been seen to be based on the deontological notion of justification (Ginet 1975, 36; Alston 1986; Plantinga 1993, chapt. 1.IV; Goldman 1999). Whether a person is epistemically responsible in forming her beliefs depends, among other things, on whether she takes into account the available evidence. However, it can only be reasonably expected from her to base her beliefs on evidence to which she can gain some access. The deontological assessment of her beliefs must therefore be relativized to her epistemic perspective. According to internalists, only directly accessible mental facts (such as beliefs, perceptual experiences or memory) ultimately belong to the range of reasons of which to take adequate notice a subject can be held responsible. ${ }^{5}$ It is a matter of debate, however, just to which extent internalism can actually rely on the deontological conception of justification. In particular, one could doubt whether the deontological conception can

4 See Conee and Feldman 2001, 233, who extract such a characterization of internalism from a survey of the literature.

5 The internalist claim that justifiers have to be mental means that external circumstances can count for justification only insofar as they are reflected by mental facts, for instance by means of logical or probabilistic relations. It is a matter of dispute, however, whether the relation between internal justifier and external fact is itself a justifier, and if so whether by internalist standards, it would have to be internally accessible. See Goldman 1999, 216-217 and Connee and Feldman 2001, 252253. 
support an accessibility condition that is narrow enough to yield internalism. Even if a deontological assessment has to be relativized to the accessible evidence, it might seem implausible that access must be special and is thus restricted to the subject's mental life. As we shall see shortly, the epistemic duties operative in science do not distinguish strictly between special access and 'ordinary' access e.g. by perception or testimony. ${ }^{6}$

Still, even if it is granted that the deontological notion alone does not give rise to internalism, the relativization of the deontological assessment to the evidence within the range of the subject's epistemic perspective persists. An alethic evaluation of beliefs, by contrast, need not include such a restriction. Since in an alethic evaluation, the actual likelihood of truth of some beliefs or the truth-conduciveness of some practice of belief formation is assessed, it must be based on whatever in fact characterizes the subject's epistemic situation and the (objective) epistemic merits of her beliefs and her belief formation. This crucial difference in the application of the two concepts allows determining whether a given epistemic evaluation of beliefs from a third-person perspective makes use of the deontological or the alethic concept of justification. Assume, for instance, that the assessment of a subject's belief is indifferent to factors that can affect the truth-conduciveness of the belief formation and that the indifference is due to the factors lying outside the subject's epistemic perspective. In such a case, the epistemic assessment must be based on the deontological notion. In another case, two evaluators might disagree on the epistemic assessment of a third person's beliefs due to a different assessment of facts that lie beyond the person's epistemic perspective. Their dispute must make use of the alethic notion of justification. In the later sections of this paper, such indicators will be used to determine whether within science and in the philosophy of science,

6 There are different positions as to whether internalism can be grounded on deontologism. Goldman (1999), for instance, argues that internalists have to assume that in addition to the deontological evaluation of beliefs, justification has to provide practical guidance to subjects on what to believe. Steup (2001b), by contrast, claims that deontologism alone is sufficient to ground internalism. Alston rejects deontologism itself. According to him, the deontological account presupposes voluntary control over one's beliefs to a degree that can often not be taken for granted. Many beliefs rather appear to be forced on us. When we see, for example, that there is a car coming down the street, we usually cannot help but form the corresponding belief. But then, deontological standards cannot apply to our belief formation (Alston 1985 and 1988). While some authors have defended the claim that our beliefs are under sufficient voluntary control (Ginet 2001, Steup 2001a), others have argued that internalism does not presuppose the deontological notion of justification (Conee and Feldman 2001). 
scientific claims are assessed according to the deontological or the alethic notion of justification.

Given the distinction of the two notions and the differences in their application, the question as to their relationship arises. In particular, the question how the deontological justification of a belief is connected to its likely truth (and hence its alethic justification) is important. Again, Alston has provided instructive contributions to this question. ${ }^{7} \mathrm{He}$ argues that subjects that are deontologically justified might still be "in a poor position to get the truth" (Alston 1988, 145) and gives the following example in support of this claim:

If I have grown up in an isolated community in which everyone unhesitatingly accepts the traditions of the tribe as authoritative, then if I have never encountered anything that seems to cast doubt on the traditions and have never thought to question them, I can hardly be blamed for taking them as authoritative. There is nothing I could reasonably be expected to do what would alter that belief-forming tendency. And there is nothing I could reasonably be expected to do what would render me more exposed to counterevidence. ... I am [deontologically] justified in believing these things. And yet the fact that it is the tradition of the tribe that $p$ might be a poor reason for believing that $p$ (Alston 1985, 95).

Alston thus envisages a situation in which a person follows some traditional modes of belief formation and thus comes to adopt some belief $p$. Even though $p$ is not well supported, the subject is taken to be free from blame because there are no reasons for the subject to doubt that the mode of belief formation and the belief are acceptable. This shows, according to Alston, that our beliefs can be deontologically justified without being alethically justified and thus without "hook[ing] up in the right way with an adequate truth-conducive ground" (ibid.).

7 In addition to the question whether deontological justification is connected to alethic justification, the issue has been discussed whether such a link is crucial for the value of deontological justification. Alston maintains that any notion of epistemic justification has to specify features that are desirable from the standpoint of the aim of maximizing truth and minimizing falsity (Alston $1985,84)$. In his view, the inclusion of aspects of alethic justification is thus necessary for the value of deontological justification. Steup, by contrast, suggests that deontological justification can add something to the value of alethically justified beliefs. In his view, deontological justification is necessary for human knowledge in a sense which includes the knowledge that we know (Steup 2001b, 147). 
Deontologists could question, however, that this case really shows that deontological justification is thus severed from truth. Matthias Steup has argued, for instance, that traditions of belief formation do not free believers from blame so easily. Rather, if a subject has no evidence whatsoever for a belief, then, according to Steup,

no matter how grim the circumstances are ... it is within his power, given that he is a rational agent, to reflect upon his belief and thereby to find out that he had better withhold it. Being a rational agent, I would say, involves the capacity to find out, with respect to any belief, whether it is being held on good grounds (Steup 1988, 78; Steup's emphases).

The argumentative strategy of the deontologist in response to Alston's case could thus be to emphasize that for somebody to be deontologically justified, she has to meet certain conditions of rationality. For instance, it could be argued that under suitable conditions, it must be clear to the subject whether the available evidence speaks for the truth of her belief. It would thus not be sufficient to accept a belief merely because it is traditional to do so, but require some amount of reflection on the part of the subject. In addition, it might be demanded that in forming and reflecting on her beliefs, the subject makes use of suitably qualified cognitive capacities, for instance to draw her conclusions. Altogether, the deontologist could argue that deontological justification presupposes that a subject is concerned about the truth of her beliefs and is so in a way that meets certain truth-conducive standards. In reply to Alston, one can thus conclude that deontological justification can be tied to truth in various ways.

Still, the main point of Alston's criticism of internalism seems to remain in place. Even if conditions of rationality of the suggested kinds are included, deontological justification cannot be taken to imply alethic justification. As long as we judge cognizers according to what can reasonably be expected from them, the range of reasons to be taken into account for belief formation or for the assessment of principles of belief formation will always be restricted to the cognizers' epistemic perspectives. Therefore, there can always be circumstances that lie beyond the epistemic perspective of some cognizers and thus need not be taken into consideration when they form their beliefs, but decisively affect the truthconduciveness of their belief-formation. Skeptical scenarios such as evil demon situations include exactly such circumstances, of course. Less drastically, one can think of situations in which there is a quite specific, yet systematic obstacle for 
somebody to form true beliefs, while the subject has good reasons to suppose otherwise. Assume that a visitor enters the barn façade region where it is local custom to put up picturesque barn façades (Goldman 1976). If the custom is largely unknown, and the country is elsewhere littered with real barns, the view of a barnlike looking construction down the hill might constitute perfectly respectable evidence for the belief that there is a barn over there. This mode of belief formation has proved to be reliable in many situations, and the visitor has no reason to suspect that it cannot be relied upon here. Yet in the barn façade region where barn façades and real barns are not distinguishable by looking from the road and where barn façades greatly outweigh real barns, the thus formed beliefs are not likely to be true and hence are not alethically justified.

At bottom, the problem faced here is to show that by forming our beliefs on the basis of the accessible evidence in a responsible way, we are in fact likely to reach the truth (cp. Kornblith 2001a, 5). The objection based on the barn façade case suggests that there is no straightforward way to resolve this problem because of the constant possibility of falsifying factors that lie beyond the responsible subject's epistemic perspective. ${ }^{8}$ It thus seems clear that two quite different notions of justification have to be distinguished, with the deontological notion referring to the justification of a subject's beliefs relative to her epistemic perspective, and the alethic notion being only concerned with the merit of beliefs with respect to truth. I will now turn to scientific justification to see whether this distinction can help to explain the observed duality in the epistemic appraisal of scientific claims.

\section{Justification in science}

In general, scientific claims are justified within science if putting forward the claims does not violate the scientific or methodological standards. For instance, a theory is scientifically acceptable if it meets requirements such as empirical accuracy, simplicity and explanatory power, and does so better than alternative theories. Whether these requirements are met depends on the scientific state-of-the-art, for instance on the existing evidence and the available theoretical alternatives. Intrascientific justification thus refers to a restricted epistemic perspective. In the

\footnotetext{
8 While I take it that the given arguments clearly establish the distinction between the two notions of justification, they are not meant to show that deontological justification ultimately fails to tie up to truth, as Alston has suggested. In any case, there are still a number of replies open to deontologists. Bonjour claims, for instance, that even if (coherentist) deontological justification is not truthconducive under all imaginable conditions, it is still likely to be so in the long run (Bonjour 1985).
} 
light of the distinction between the two notions of justification, the scientific epistemic assessment thus appears to focus on the deontological notion.

On reflection, such an emphasis of the deontological notion in scientific practice should not come as a great surprise. Since deontological standards have to be such that it can reasonably be expected from scientists to follow them, they can be operative in scientific practice. They directly prescribe or recommend certain epistemic actions such as to compare the available empirical evidence for alternative theories or to assess their simplicity, and to choose among the theories accordingly. In contrast to this, it is much less clear how the alethic justification of alternative theories should be assessed. It seems much more difficult, for instance, to assess the actual truth-conduciveness of the set of theoretical virtues, and clear guidance concerning specific epistemic action is much less likely to follow from attempts at such an assessment. Therefore, the alethic notion cannot be applied to assess scientific beliefs in a similarly straightforward way and is therefore difficult to directly implement in scientific practice.

However, contrary to the way in which internalism usually spells out the deontological conception, the scientific notion of justification includes a much wider accessibility condition. Firstly, the distinction between privileged and just ordinary access does not seem to play a central role in the scientific justificatory practice. If some measuring results show up on a screen, the experimenter has the duty to take them into account. The question whether she is in fact justified in trusting her experiences does not arise as long as there are no specific reasons for suspicion. In any case, she need not be able to answer this question only on the basis of evidence to which she has special access. For the purposes of scientific justification, foundational beliefs are not confined to facts to which we have special access.

Secondly, not only the reasons personally accessible to the scientist, but any reasons possessed by the scientific community have to be taken into account. A scientist can be blamed, e.g., for ignoring published evidence that contradicts some theory she accepts. In this respect, the scientific notion of justification pays tribute to the fact that science is a communal project of knowledge gathering.

The social character of science shows up in further features of scientific justification. As a matter of fact, only the extensive division of labor between scientists across history, different subdisciplines and different specializations (as experimenters, theorists etc.) makes today's scientific findings humanly achievable. This seems to lead to two different social conditions on some individual scientist's 
justification. Firstly, scientific results have to be taken into account by a scientist even though she cannot comprehensively redo their scientific assessment herself. The standards of justification often demand from her to trust reports that have been assessed by other scientists. Secondly, some scientist's justification in accepting a theory not only depends on evidence provided by others, but can to some degree also depend on whether those others were justified in putting forward the evidence. If they have produced the data very carelessly or even fraudulently, not only the claims of the producers of the evidence, but also the theorist's belief may be unjustified by scientific standards.

Plausibly, the social character of scientific knowledge gathering explains the prominent status of the intrascientific epistemic assessment. An assessment of existing scientific claims according to the best available scientific knowledge is crucial to determine whether further inquiries should rely on them. Since the epistemic perspective of the scientific community must be the basis of this assessment, it is to be expected that the intrascientific assessment makes use of the deontological notion of justification.

Still, despite of the first appearance that scientific justification is mainly deontological, also the truth-conduciveness of modes of producing scientific results is often explicitly addressed in science. This applies in particular to observations and the generation of empirical results. One might wonder whether in these instances, it is not the alethic rather than the deontological notion that plays the central role in scientific practice. I will address this issue by looking more closely at the scientific standards for assessing the reliability of observation results.

\section{Assessing the reliability of observation results}

Observational data come in a wide variety in the sciences. At one extreme, there are empirical results that are obtained by highly complex experiments. The reliability and thus the truth-conduciveness of the observation processes is often studied extensively in these cases before the observation results are put forward as scientifically justified. Do these cases show that the scientific assessment of observation results also employs the alethic notion of justification?

The experimental finding that the neutrinos emitted by the sun arrive at the earth in all three types (or 'flavors') is a good example to look at this question more closely. This finding has been established by experiments at the Sudbury Neutrino Observatory in Canada (Ahmad et al. 2001 and 2002). The result is important since it 
offers a solution to the solar neutrino problem. The problem arises from a discrepancy between the neutrino fluxes as predicted by the standard solar model and as measured by previous neutrino experiments. The previous experiments, which only detected one type of neutrinos, namely electron neutrinos, invariably found a flux much too low compared to the theoretical predictions. Even though it is only electron neutrinos that are produced by solar fusion and decay processes, it seems theoretically possible that some of the neutrinos change their flavor under way. Since the total flux measured by the Sudbury experiments were in agreement with the standard solar model, the result has been taken as evidence for such a neutrino flavor transformation.

The experiments required considerable efforts. The detector consisted of a vessel with a diameter of 12 meters that was filled with 1000 tons of heavy water. It was deposited in a copper mine 2000 meters below the surface. More than 9000 photomultiplier tubes were placed around it to register sparks (Čerenkov radiation) that occur in the heavy water. The data were collected over a period of more than a year.

For such data, reliability is not something that can be taken as given, but has to be established. A wide range of measures were taken to accomplish this. The detector was buried deep under the surface in order to shield it from cosmic rays. In addition, the heavy water was protected from gamma rays and neutrons emitted by the rock by an additional 7000 tons of light water. An important role was played by the calibration of the detector. With artificial optical and radioactive sources, the optical properties of the apparatus and its sensitivity to beta- and gamma-rays and to neutrons were determined. One of the things to be learned was how to reconstruct the energy and direction of the events from the pattern of responses of the photomultiplier tubes. The calibration was aimed at distinguishing three types of interactions between neutrinos and heavy water, each of which lead to characteristic radioactive radiation. Since the three flavors of neutrinos are differentially likely to interact in the three ways, their proportion can be determined by comparing the counting results for the three different interactions (Sudbury Neutrino Observatory 2006).

The data reduction was another important step in the generation of the empirical results. In the first round of the experiments, from the more than 300 million initially triggered events, about 1000 have been selected as the relevant data base. The data selection followed, on the one hand, the results from the calibration. The 
instrumental background due to electric discharges in the photomultiplier tubes, for example, was excluded because it produced a response pattern different from the one that had been determined for Čerenkov radiation in the heavy water. On the other hand, the signal-to-noise ratio was improved by data cuts. For example, low energy radioactivity backgrounds were removed by setting a high energy threshold for events to be further processed (Ahmad et al. 2001).

Altogether, a large number of both empirical and theoretical considerations about the process of data generation and selection were adduced to assess the final results. This shows that science is both directly concerned with truth and epistemically selfconscious. The question whether some observation process is truth-conducive is often explicitly addressed, and everything known scientifically about the observation process that bears on its reliability enters into the epistemic assessment. In addition, many measures are undertaken specifically to increase the reliability or to gain additional empirical data that show how to improve it.

Still, this does not mean that science is here committed to the alethic notion of justification. While the reasons concern the truth-conduciveness of the observation processes, only reasons accessible to the scientific community matter. For example, the theoretical understanding of the different processes of neutrino interaction is of central importance for gaining the result. Otherwise, it would not be clear which characteristic signals to look for and hence how to calibrate the detector or how to select the data. But it is the standard theories that enter here as conditions of justification, not the real processes that take place. If in retrospect, we would find that contemporary physics was wrong about the neutrino interactions, we would still think that the physicists were scientifically justified in accepting the results if the error is not their fault.

In a similar way, assume that by a mode of electrical communication that is as yet unknown to science, the photomultiplier tubes conspired in such a way as to produce fake records of events that echo the real neutrino events. This effect falsified the experimental result. Even though the results were unreliable under these conditions, the scientists would have been scientifically justified in accepting the results. They would not have been obliged to test against the echo-conspiracy possibility since this possibility appeared highly improbable from concurrent scientific knowledge.

Both this and the previous scenario show that systematic errors, if not to be expected scientifically, do not undermine the status of observation results as 
scientifically justified. Only if the scientists had indications of the theoretical flaws or the falsifying effects, they would have to investigate further into these scenarios before putting forward their claims. As long as the scenarios appear to be purely hypothetical, scientific justification does not presuppose that they are ruled out. Clearly, this is because it cannot reasonably be demanded from scientists to rule out possibilities that lie entirely beyond what is to be expected on the basis of available scientific knowledge. Scientists are required to be concerned about the truthconduciveness of observations only in so far as it lies within the scientific epistemic perspective. The actual truth-conduciveness of the observation methods is no precondition of their justification. Scientific justification means deontological justification here.

\section{Scientific realism and the alethic assessment of science}

Does this suggest that the alethic requirement of justification has no role to play with respect to science? This conclusion would be rash. For as noted in section 1, the assessment of scientific claims typically comes in two varieties. On the one hand, empirical results or scientific theories are assessed within science and in accordance with scientific methodological standards. As sections 3 and 4 suggest, the deontological notion dominates in these cases. On the other hand, there is a rich philosophical discourse on the justification of scientific claims. Concerning the justification of belief in scientific theories, arguments such as the abductive nomiracle argument or the pessimistic meta-induction have been adduced (Boyd 1973; Boyd 1984, 59; Laudan 1981). Does this discourse employ the alethic notion of justification?

Since those arguments are well-known and widely discussed, and the aim here is not to argue for or against scientific realism, I will restrict the presentation of the arguments to those features that make clear the kind of epistemic assessment involved (for more, see e.g. Leplin 1984; Psillos 1999). According to Richard Boyd, scientific realism holds that scientific theories can often be taken to be approximately true when confirmed according to the ordinary methodological standards of science, and successive theories typically are increasingly accurate approximations to the truth. Scientific terms are understood to putatively refer to and describe an independent reality (Boyd 1984, 41-42). In a very brief form, Boyd's abductive argument then has the following shape: 
(1) Scientific methods are heavily dependent on accepted scientific theories.

(2) These methods yield increasingly reliable empirical predictions.

Hence (by inference to the best explanation): The accepted scientific theories are approximately true and increasingly approximate the truth. ${ }^{9}$

Since the form of the argument is intended to be an inference to the best explanation, the conclusion is taken to follow because it is claimed to explain best the conjunction of the two premises. The first premise captures the phenomenon that has also been seen with the Sudbury Neutrino Experiments: Scientific methods demand that the best available scientific knowledge is employed in the scientific search for new knowledge. (The standards for claims to be acceptable as knowledge here are, of course, the deontological standards of science.) The theories that are confirmed in accordance with scientific standards form therefore a part of the presupposed background of scientific inquiry. This inquiry leads to growing empirical success, as the second premise claims. As Boyd describes it, the scientific enterprise therefore includes a dialectical process of building on accepted scientific claims in expanding and improving this knowledge. The viability of this strategy is taken to be best explained by scientific realism.

However this argument is to be evaluated, it is manifest from its conclusion that it aims at an alethic assessment of theoretical scientific claims. It claims that science is likely, given adequate conditions, to yield theories that are (approximately) true. This finding is confirmed by a counterargument to scientific realism, namely Laudan's pessimistic meta-induction (Laudan 1981). According to Laudan, the historical records show that many theories in the history of science at their time fulfilled the conditions of the abductive argument (such as empirical success), yet their theoretical assumptions can no longer be taken to be true or even approximately true. These findings are the basis for an argument against scientific realism which, in its roughest outlines, has the following form:

(1) Many past theories were empirically successful, yet they were not approximately true.

Hence (by induction): Present day empirically successful theories are not likely to be approximately true.

9 Cp. Boyd (1984, 59). For a more detailed reconstruction with the same overall argument structure see Psillos (1999, 78). 
Again, the very formulation of the conclusion shows that the argument aims at assessing theoretical scientific claims according to the alethic requirement. Further confirmation is provided by a closer analysis of the argument. The argument rests on the premise that earlier theories that were positively assessed at their time now have to be dismissed, since our present scientific knowledge shows, for instance, that postulated entities that feature centrally in these theories do not exist. The assessment of the earlier theories is thus not relativized to the epistemic perspective of their historical adherents. We do not aim to assess whether the earlier scientists did what can reasonably be expected from them, but whether the theories are in fact good from the perspective of the assumed aim of science, namely to deliver true accounts of the world. The assessment is therefore not based on the deontological notion, but on the alethic notion of justification. If the argument is to avoid equivocation, the very same notion also has to occur in its conclusion. In addition, since it is agreed that the conclusion contradicts the no-miracle argument, also the latter's conclusion has to employ the alethic notion.

\section{Relating the two assessments}

The discussion so far has shown that the duality of epistemic assessments rests on two different notions of justification which give rise to an intrascientific and a philosophical evaluation of science. ${ }^{10}$ The discussed examples suggest that the two assessments differ in the scope of scientific claims that are assessed. While intrascientific assessments seem to be concerned with a particular set of empirical results or with a particular theory, the philosophical assessment is much broader and concerns, in the case of scientific realism, all empirically successful theories. This difference in the focus of attention comes along with different types of reasons that are typically adduced. As seen, the dispute on scientific realism turns on such topics as the justification of abductive inferences or on historical cases. As the actual debates show, the case depends on a wide variety of further issues. Boyd, for instance, identifies the causal theory of reference and epistemological naturalism as important further elements in the overall realist package (Boyd 1990, 383). Scientific assessments, in contrast, are typically based mainly on reasons that speak specifically

10 The labels 'intrascientific' and 'philosophical' notwithstanding, philosophical questions of justification have of course also been addressed by scientists. Jean Perrin, for instance, not only provided scientific reasons for the existence of atoms, but also addressed the alethic justification of inferences from observables to unobservables. Still, it remains possible to distinguish between the two discourses. See the introduction of Perrin 1913 and Achinstein (2002, 489ff.) for an analysis. 
for or against a particular claim or theory. The acceptability of the Sudbury Neutrino results, for example, depends on the theories of neutrino interaction, on the calibration of the detector and on the tailor-made data analysis.

The analysis in terms of two notions of justification seems to contradict the widely shared view that the duality is mainly a matter of two different levels of epistemic assessment. As seen in section 1, the philosophical assessment has often been portrayed as being 'meta', i.e. as having the scientific justificatory standards as its proper object, while the scientific assessment is exclusively concerned with factual scientific claims. Fine accordingly distinguishes ground-level and meta-level abductive reasoning within Boyd's conception, and understands Boyd's realist argument to lie on the second, methodological level (cp. section 1). In a similar way, Laudan has drawn a general distinction between the justification of scientific claims and the justification of methodological standards. While standards are used to assess scientific claims, these standards themselves are assessed according to their effectiveness in furthering our epistemic ends. Accordingly, two levels of epistemic assessment, base-level scientific and methodological, are distinguished (Laudan 1984, 1987). ${ }^{11}$

The first thing to note here is that, in view of the given examples, the two types of assessment primarily aim at justifying the same epistemic attitude, namely belief of scientific claims. In this respect, the conclusions of the scientific and the philosophical evaluations are on the very same level. ${ }^{12}$ From the structure of the nomiracle argument as well as the pessimistic meta-induction, it is clear that their direct aim is to assess scientific claims, not scientific methods, and to license (or to ban) belief in these claims, not belief in the justification of the methods. Insofar, these arguments seem to run counter to the metaphilosophical assumptions of their authors.

11 In addition, Laudan holds that scientific findings can themselves enter as reasons into the (in my terminology) philosophical assessment of scientific methods (Laudan 1987). I will turn to this naturalistic aspect of the conception below. Furthermore, Laudan holds that the negotiations of the aims of scientific research are part of the naturalized philosophical discourse (Laudan 1984). According to Laudan, methods are often assessed with respect to different epistemic aims, while I have throughout this paper assumed that (suitably qualified) truths constitute that aim. Still, even if this complication is included, the relation of the two assessments and the concentration of Laudan's philosophical assessment on methods remain unaltered.

12 The anti-realist philosophical arguments do of course not aim at justifying belief in scientific theories. Yet, also by arguing for anti-realist attitudes such as belief in the empirical content of scientific theories, they address epistemic attitudes towards scientific factual claims and have in this sense the same objects as intrascientific assessments. 
At the same time, it has to be conceded that the given philosophical arguments include an assessment of the truth-conduciveness of scientific methods. The first premise of the abductive argument for scientific realism, for instance, alludes to the fact that accepted theories enter into the intrascientific assessment of scientific claims. It thus refers to the standards which govern both the assessment of scientific claims and their further use within science. Since the abductive argument aims at showing that scientific theories that are arrived at in accordance with those standards are likely to be true, it shows, if valid, that the scientific standards are truthconducive. This amounts to an implicit justification of these standards or methods. Yet, even if the argument implicitly assesses scientific methods, it still has an assessment of the epistemic status of base-level scientific claims as its conclusion. The epistemological thesis of scientific realism must be based on exactly such an assessment. It can therefore hardly be seen why the argument should not be taken at face value and be read as aiming at an assessment of factual scientific claims as well.

In fact, the relation between method and product is reminiscent of reliabilism as an account of alethic justification in general epistemology. The reference to the reliable generation of belief is often intended to capture the intuition that a true belief would not qualify as knowledge if its truth was merely accidental. Reliability is referred to, for instance, to rule out the possibility that despite of the subject taking there to be good reasons for the belief and the belief being in fact true, the truth of the belief is a mere coincidence given the way it has been formed. Similarly, the reference to reliable scientific methods in the epistemology of science could be understood as intended to rule out the possibility that the truth of scientific claims is only accidental, and hence to rule out the possibility that even if scientific claims are true, they are not justified alethically. If this reconstruction is correct, then one would confuse means and end if one assumed that scientific methods are the primary object of the philosophical account.

The claim that there is no general difference of levels in the objects of the two assessments is also supported by the observation that methodological rules are regularly assessed intrascientifically. In particular, from general methodological rules, more specific rules are often derived with the help of scientific findings. For instance is the specific rule that in medicine, therapeutics should be tested doubleblind, strongly commended by the specific finding that the placebo effect can influence the results of clinical tests in conjunction with the general rule that expected sources of error should be controlled. When such a specific methodological 
rule is established, it will be assessed according to the scientific state-of-the-art, for instance according to our best available knowledge on the placebo effect. Methodological rules are thus not an exclusive object of philosophical assessment, but can also be subject to intrascientific, deontological evaluation. This confirms the conclusions that the alethic assessment is not to be identified with methodology and that the duality of epistemic assessments cannot be analyzed by recourse to the distinction between the justification of scientific claims and the justification of methodological standards.

The question remains, however, how the two assessments are related. As suggested by the examples, the assessments differ in the scope and the kinds of reasons that are adduced, with the philosophical assessment tending to be fairly general and being based on broad assumptions on our epistemic situation (e.g. the causal theory of reference or the overall historical discontinuities in scientific theoretical ontologies), while the scientific assessment concerns particular methods or claims and is based on specific scientific reasons. Still, the philosophical assessment cannot simply be a generalization of scientific assessments since due to the different notions of justification involved, the evaluations differ in content.

From the very notions that are involved in the assessment, one would expect that the normative force of the intrascientific assessment depends ultimately on the alethic assessment. As seen in section 2, it remains a major task of the deontological account of justification to show that by following the set of epistemic standards, we are in fact likely to attain the truth. When some alethic assessment of scientific knowledge gathering would show that certain scientific standards are not in fact truth-conducive, this could undermine the status of the standards as scientifically obligatory.

However, the overall relationship of the two assessments also depends on whether one takes the philosophical assessment to be naturalized (as both Laudan and Boyd do). From the perspective of a naturalized philosophy of science, many premises that are adduced within the philosophical assessment derive their status as reasons from being scientifically justified. This means that the philosophical debates on the alethic justification of scientific claims will be fueled also by claims that are positively assessed according to the scientific deontological standards. In this case, the - in principle - normative dependency of the intrascientific on the philosophical assessment goes hand in hand with an opposite dependency concerning the reasons used in the philosophical assessment. It thus seems that while the two assessments 
focus on different aspects of an overall justificatory task, they depend on each other in intricate ways. ${ }^{13}$

\section{References}

Achinstein, P.: 2002, Is there a valid experimental argument for scientific realism? Journal of Philosophy 99, 470-495.

Adam, M.: 2004, Why worry about theory-dependence? Circularity, minimal empiricality and reliability, International Studies in the Philosophy of Science $18,117-132$.

Ahmad, Q. et al.: 2001, Measurement of the Rate of $v_{e}+d \rightarrow p+p+e^{-}$Interactions Produced by ${ }^{8} \mathrm{~B}$ Solar Neutrinos at the Sudbury Neutrino Observatory, Physical Review Letters 87 (7), 071301, 1-6.

Ahmad, Q. et al.: 2002, Direct Evidence for Neutrino Flavor Transformation from Neutral-Current Interactions in the Sudbury Neutrino Observatory, Physical Review Letters 89 (1), 011301, 1-6.

Alston, W. P.: 1985, Concepts of Epistemic Justification, in W. P. Alston 1989, 81114.

Alston, W. P.: 1986, Internalism and Externalism in Epistemology, in W. P. Alston 1989, 185-226.

Alston, W. P.: 1988, The Deontological Conception of Epistemic Justification, in W. P. Alston 1989, 115-152.

Alston, W.: 1989, Epistemic Justification, Cornell University Press, Ithaka.

Bonjour, L.: 1985, The Structure of Empirical Knowledge, Harvard University Press, Cambridge MA.

Boyd, R.: 1973, Realism, Underdetermination, and a Causal Theory of Evidence, Noûs 7, 1-12.

13 I would like to thank Ansgar Beckermann, Martin Carrier, Christian Nimtz, Torsten Wilholt and the anonymous reviewers as well as audiences at the 26th Wittgenstein Symposium 2003 (Kirchberg) and the SIFA Congress 2004 (Genoa) for helpful comments on earlier versions of this paper. 
Boyd, R.: 1984, The Current Status of Scientific Realism, in Leplin, J. (ed.), Scientific Realism, University of California Press, Berkeley, pp. 41-82.

Boyd, R.: 1990, Realism, Approximate Truth, and Philosophical Method, in C. Wade Savage (ed.), Scientific Theories, Minnesota Studies in the Philosophy of Science, Vol. 14. University of Minnesota Press, Minneapolis, pp. 355-391.

Brown, H. I.: 1993, A Theory-Laden Observation Can Test The Theory, British Journal for the Philosophy of Science 44, 555-559.

Conee, E. and R. Feldman: 2001, Internalism Defended, in H. Kornblith (ed.) 2001, 231-260.

Culp, S.: 1995, Objectivity in Experimental Inquiry: Breaking Data-Technique Circles, Philosophy of Science 62, 430-450.

Fine, A.: 1984, The Natural Ontological Attitude, in J. Leplin (ed.), Scientific Realism, University of California Press, Berkeley, pp. 83-107.

Foley, R.: 1998, “Justification, epistemic”, in E. Craig (ed.), Routledge Encyclopedia of Philosophy, Vol. 5. Routledge, London, pp. 157-165.

van Fraassen, B.: 1980, The Scientific Image, Oxford University Press, Oxford.

Ginet, C.: 1975, Knowledge, Perception, and Memory, Reidel, Dordrecht.

Ginet, C.: 2001, Deciding to Believe, in M. Steup (ed.) 2001, 63-76.

Goldman, A. I.: 1976, Discrimination and Perceptual Knowledge, Journal of Philosophy 73, 771-791.

Goldman, A. I.: 1979, What is Justified Belief? in G. S. Pappas (ed.), Justification and Knowledge, Reidel, Dordrecht, pp. 1-23.

Goldman, A. I.: 1986, Epistemology and Cognition, Harvard University Press, Cambridge, MA.

Goldman, A. I.: 1999, Internalism Exposed, in H. Kornblith (ed.) 2001, 207-230.

Kitcher, P.: 2001, Science, Truth, and Democracy, Oxford University Press, Oxford.

Kornblith, H. (ed.): 2001, Epistemology: Internalism and Externalism, Blackwell, Malden.

Kornblith, H.: 2001a, Internalism and Externalism: A Brief Historical Introduction, in H. Kornblith (ed.) 2001, 1-9.

Kosso, P.: 1989, Science and Objectivity, Journal of Philosophy 86, 245-257.

Lakatos, I.: 1971, History of science and its rational reconstructions, in I. Lakatos: 1978, The methodology of scientific research programmes, Philosophical Papers, Vol. 1. Edited by J. Worrall and G. Currie, Cambridge University Press, Cambridge, pp. 102-138. 
Laudan, L.: 1981, A Confutation of Convergent Realism, Philosophy of Science 48, $19-48$.

Laudan, L.: 1984, Science and Values. The Aims of Science and Their Role in Scientific Debate, University of California Press, Berkeley.

Laudan, L.: 1987, Progress or Rationality? The Prospects for Normative Naturalism, American Philosophical Quarterly 24, 19-31.

Perrin, J.: 1913, Les Atomes, Alcan, Paris.

Plantinga, A.: 1993, Warrant: The current debate, Oxford University Press, New York.

Psillos, S.: 1999, Scientific Realism. How science tracks truth, Routledge, London.

Steup, M.: 1988, The Deontic Conception of Epistemic Justification, Philosophical Studies 53, 65-84.

Steup, M. (ed.): 2001, Knowledge, Truth, and Duty, Oxford University Press, Oxford.

Steup, M.: 2001a, Introduction, in M. Steup (ed.) 2001, 3-18.

Steup, M.: 2001b, Epistemic Duty, Evidence, and Internality, in M. Steup (ed.) 2001, 134-148.

Sudbury Neutrino Observatory: 2006, The SNO Detector, http://www.sno.phy.queensu.ca/sno/sno2.html, last accessed 13 March 2006. 